\title{
Numerical study of the effects of crack location on creep crack growth in weldment
}

\author{
M. Saber ${ }^{\mathrm{a}^{*}}$, W. Sun ${ }^{\mathrm{b}}$ and T. H. Hyde \\ ${ }^{a}$ Faculty of Engineering, Port Said University, P. O. Box: 42526, Egypt \\ ${ }^{\mathrm{b}}$ Department of Mechanical, Materials and Manufacturing Engineering, \\ University of Nottingham, Nottingham NG7 2RD, UK
}

\begin{abstract}
*Correspondence author
E-mail: mohammed.saber@eng.psu.edu.eg

Telephone: +201009890161
\end{abstract}

\begin{abstract}
A numerical study on the effects of crack location on creep crack growth (CCG), in a P91 weldment, was carried out. The P91 weldment consists of parent material (PM), weld metal (WM) and heat-affected zone (HAZ). Models of compact tension (CT) specimen were used. These models are single material CT models, i.e. PM and WM, bi-material CT models, i.e. PMHAZ and PM-WM, and three-material CT models, i.e. PM-HAZ-WM. A commercial Finite Element (FE) package (ABAQUS) was used to conduct the study. The results obtained showed that, the CCG and the CCG rates in the WM CT models are much higher than those in the PM CT models. However, the CCG in cross-weld specimens is controlled by the properties of the weaker component of the weld. This highlights the importance of the HAZ as the weakest region of the weldments.
\end{abstract}

Keywords: P91, damage mechanics, finite element method, creep crack growth. 


\section{Nomenclature:}

$\begin{array}{ll}\mathrm{A} & \text { Material constant in Norton's creep law, Kachanov creep damage model, } \\ \mathrm{a} & \text { and Liu and Murakami creep damage model } \\ \mathrm{B} & \text { Crack length } \\ & \text { Material constant in Kachanov creep damage model or } \\ \mathrm{n} & \text { full thickness of compact tension specimens } \\ & \text { Material constant in Norton's creep law, Kachanov creep damage model, } \\ \mathrm{q}_{2} & \text { and Liu and Murakami creep damage model } \\ \mathrm{t} & \text { Material constant in Liu and Murakami creep damage model } \\ \mathrm{t}_{\mathrm{f}} & \text { Time } \\ \alpha & \text { Failure time } \\ \varepsilon_{i j} & \text { Multiaxial parameter; material constant } \\ S_{i j} & \text { Creep strain tensor } \\ \sigma_{e q} & \text { Deviatoric stress tensor } \\ \sigma & \text { Equivalent, von Mises, stress } \\ \sigma_{1} & \text { Stress } \\ \sigma_{\mathrm{r}} & \text { Maximum principal stress } \\ \chi & \text { Rupture stress } \\ \omega & \text { Material constant in both Kachanov, and Liu and Murakami creep damage } \\ \varepsilon & \text { models } \\ \dot{\varepsilon} & \text { Damage parameter, ranging from 0.0 (no damage) to 1.0 (full damage) } \\ \phi & \text { Creep strain }\end{array}$

\section{INTRODUCTION}

Welding is an unavoidable manufacturing process in building up conventional power plants, nuclear power plants or chemical plants. Some of the components of these plants operate at temperatures which are high enough to cause their materials to creep. When cracks exist at the weldment of these components, the situation is getting worse and these weldments become a life limiting of the components and, possibly, of the whole plant. Four different types of cracks could be found in welding region[2], namely Type I, Type II, Type III and Type IV, as shown in Figure 1. Type I cracks occur within the WM, either horizontal or vertical. Type II cracks initiate in the 
WM and grow cross the HAZ. Similar to Type I cracks, Type II cracks could be horizontal or vertical. Type III cracks initiate and grow in the coarse grained HAZ. They normally grow toward the root of the weld. Type IV cracks grow in fine-grained HAZ. Similar to Type III cracks, Type IV cracks grow toward the root of the weld. In the pipe work, Type IV cracking is extremely important as it grows in the weakest zone of the weld and is often the cause of the failure of the weld[2].

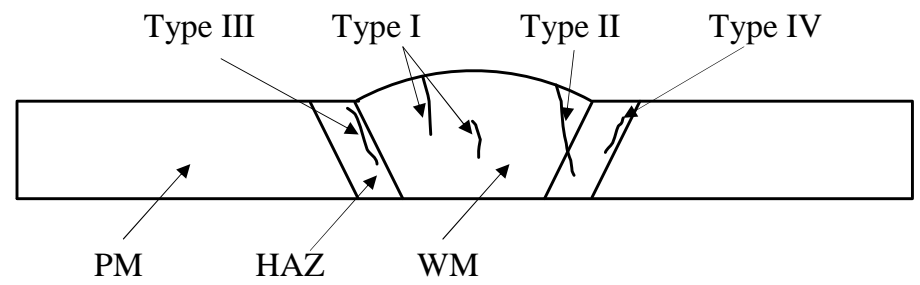

Figure 1: Four different types of cracks could be found in welded zone.

Creep crack growth of Type IV cracks, for ferretic steels, has been extensively studied both experimentally and numerically e.g. [3-7]. Hyde et al [8] predicted creep crack growth in a P91 weld, at $650^{\circ} \mathrm{C}$, using $\mathrm{FE}$ analyses. Compact tension specimens were used in the experimental study and the corresponding CT models were used in the FE analyses. The results of those analyses were compared to the experimental results and good correlation was obtained [8-9]. This correlation encourages the authors to apply the same modeling techniques to model problems for which we do not have experimental data. Another motivation to conduct this study is the lack of studies on the CCG behaviour in the welds which have different types of cracks, i.e. Type I, Type II, Type III and Type IV. Therefore, in this paper, a numerical study which compares the behaviour of these types of cracks is presented. Models of single-material CT specimens and of multi-material, across-weld, CT specimens were used. Initial cracks were 
located at different positions to represent different types of cracks. 2D FE analyses were carried out using a commercial FE package (ABAQUS) and the material properties for a P91 weld, at $650^{\circ} \mathrm{C}$. The results obtained from the $\mathrm{FE}$ analyses on across-weld CT models were compared to those obtained from single material CT models.

\section{MATERIALS}

The material studied is a modified $9 \mathrm{Cr}$ ferretic power plant steel. The $9 \mathrm{Cr}$ steel was firstly developed in the US in 1980s [9] as an alloy steel with high creep resistance. The 9Cr was, primarily, used in main steam pipes in coal fired power stations. However, in order to maximize the benefit of burning fuel and to reduce the emission of $\mathrm{Co}_{2}$, power plants had to operate at higher temperatures and higher pressures. Therefore, new materials were needed. Hence, the $9 \mathrm{Cr}$ steel was subjected to modifications and the modified-9Cr steel (P91) was manufactured.

Metal arc welding is the common welding technique used for welding P91 pipes. In order to obtain high strength of the weldment, consumables made of P91WM were often used. The chemical compositions of P91 PM and WM are shown in Table 1. Heat affected zone is a parent material affected by the heat produced during the welding process. Therefore, its chemical composition is the same as that for the PM. However, the creep properties for the HAZ are different from those for the PM.

Table 1: Chemical compositions of P91 PM and WM, wt\%, [10].

\begin{tabular}{|c|c|c|c|c|c|c|c|}
\hline Element & $\mathrm{C}$ & $\mathrm{Mn}$ & $\mathrm{Si}$ & $\mathrm{Cr}$ & $\mathrm{Mo}$ & $\mathrm{N}$ & $\mathrm{Ni}$ \\
\hline $\mathrm{PM}$ & 0.11 & 0.36 & 0.022 & 8.74 & 0.98 & 0.048 & 0.12 \\
\hline $\mathrm{WM}$ & 0.087 & 1.07 & 0.28 & 8.6 & 1.02 & 0.04 & - \\
\hline
\end{tabular}




\section{MATERIAL BEHAVIOR MODELS}

Cross-weld CT specimens consist of three material zones: PM, HAZ and WM. These three materials are assumed to be homogenous, isotropic and follow Norton's creep law, i.e.

$$
\dot{\varepsilon}=A \sigma^{n}
$$

where $\mathrm{A}$ and $\mathrm{n}$ are material constants.

A coupled creep/damage model proposed by Liu and Murakami [1] was used to predict damage in the P91 CT models. Fully damaged elements near the crack tip are used to represent crack growth (see Section 5). The multiaxial form of the model is given by[1]:-

$$
\frac{d \varepsilon_{i j}^{c}}{d t}=\frac{3}{2} A \sigma_{e q}^{n-1} S_{i j} \operatorname{Exp}\left[\frac{2(n+1)}{\pi \sqrt{1+3 / n}}\left(\frac{\sigma_{1}}{\sigma_{e q}}\right)^{2} \omega^{3 / 2}\right]
$$

and the uniaxial form the equation is given by:-

$$
\frac{d \varepsilon^{c}}{d t}=A \sigma^{n} \operatorname{Exp}\left[\frac{2(n+1)}{\pi \sqrt{1+3 / n}} \omega^{3 / 2}\right]
$$

Damage $\omega$ is evaluated using:-

$$
\frac{d \omega}{d t}=\frac{B(1+\phi)\left[1-\operatorname{Exp}\left(-q_{2}\right)\right]}{q_{2}}\left(\sigma_{r}\right)^{\chi} \operatorname{Exp}\left(q_{2} \omega\right)
$$

in which $\sigma_{\mathrm{r}}$ is the rupture stress, i.e.

$$
\sigma_{r}=\alpha \sigma_{1}+(1-\alpha) \sigma_{e q}
$$

Where $\sigma_{1}$ and $\sigma_{\mathrm{eq}}$ are the maximum principal stress and the equivalent stress, respectively, and $\alpha$ $(0<\alpha<1)$ is a material constant related to the multi-axial stress state within the material.

Integration of Eqn. (4) under uniaxial conditions leads to:- 


$$
\omega=-\frac{1}{q_{2}} \operatorname{Ln}\left[1-\left(1-e^{-q_{2}}\right) \frac{t}{t_{f}}\right]
$$

where

$$
t_{f}=\frac{1}{B(1+\phi) \sigma^{\chi}}
$$

$A, n, B, \chi, q_{2}$ and $\phi$ are material constants which can be obtained by curve fitting to the uniaxial creep curves. The value of the multi-axial parameter $\alpha$ is obtained by fitting the failure times of notched bar specimens, made of the PM, the WM and across the weld, to those of FE notched bar models of the PM, WM and across the weld, respectively. Procedures used to obtain these constants are given in [11] and summarised in [12]. The values of the material constants are given in Table 2, [12].

Table 2: P91 material constants for damage constitutive equations at $650{ }^{\circ} \mathrm{C}$ ( $\sigma$ in $\mathrm{MPa}$ and time in $\mathrm{h}$ ),

[12]

\begin{tabular}{llllllll}
\hline Material & $A$ & $n$ & $B$ & $\phi$ & $\chi$ & $q_{2}$ & $\alpha$ \\
\hline PM & $1.092 \times 10^{-20}$ & 8.462 & $3.537 \times 10^{-17}$ & 7.346 & 6.789 & 3.2 & 0.3125 \\
WM & $1.370 \times 10^{-20}$ & 7.65 & $1.600 \times 10^{-20}$ & 11.463 & 7.950 & 5.0 & 0.81 \\
HAZ & $2.300 \times 10^{-20}$ & 8.462 & $1.522 \times 10^{-14}$ & 7.346 & 5.502 & 2.8 & $\approx 0.5$ \\
\hline
\end{tabular}

\section{FINITE ELEMENT MODELS}

Geometries and dimensions of the CT models used throughout this study are shown in Figure 2.

Single material CT models, shown in Figure 2 (a), are the PM model and the WM model.

Experimentally, it is possible to cut out PM and WM CT specimens, of a weldment, and to test them under creep conditions. However,due to the small size of the HAZ region (normally 2-4mm width), it is not possible to cut out (and hence to test) HAZ CT specimens, unless simulated HAZ material is used. Therefore, only the PM and WM CT's were modelled using the single-material 
model. In all cases, the initial crack length is $15.5 \mathrm{~mm}$ and the specimen width is $32 \mathrm{~mm}$ and, hence, the ratio a/w is about 0.48 . This ratio conforms with the specifications of the $\mathrm{CT}$ specimens which were mentioned in ASTM-1457-00 [13]. In all of the CT models, the initial crack was located at the mid-way between the two loading point.

Two bi-material CT models were used in the current study. The first model consists of PM and HAZ; namely PM-HAZ model. The second model consists of PM and WM; namely PM-WM model. In the bi-material models, the initial crack was located on the materials interface, as shown in Figure 2 (b).

The three-material CT model, shown in Figure 2 (c), consists of PM, HAZ, and WM. Dimensions and geometry of this model are the same as those used in the experimental program, [11]. The width of the HAZ in the model is $2.4 \mathrm{~mm}$. Three different configurations of the model were used, as summarized in Table 3. In the first configuration, the initial crack was located at the PM-HAZ boundary, namely 3mat-PM/HAZ model. The crack in this configuration represents the Type IV crack in a weld. In the second configuration, the initial crack was located at the WM-HAZ boundary, namely 3mat-WM/HAZ model. The crack in this configuration represents the Type III crack in a weld. In the third configuration, the initial crack was located in the middle of the sandwiched HAZ, namely 3mat-middle-HAZ. The three models were analyzed under the same loading conditions. 
Table 3: Locations of the initial cracks in three-material models.

\begin{tabular}{ll} 
Model & Location of the initial cracks \\
\hline 3mat-PM/HAZ & on the PM-HAZ interface \\
3mat- middle-HAZ & at the middle of HAZ \\
3mat-PM/WM & on the PM-WM interface
\end{tabular}

A finite element commercial package (ABAQUS) [14] was used to carry out the FE analyses. 2D plane stress elements were used to model all of the CT models, see Figure 3. In order to minimize the processing time, fine elements were used in the vicinity of the crack tip while coarse elements were used elsewhere. Materials properties were implemented into the analyses by using CREEP subroutine. The CREEP subroutine works in junction with the FE analyses to calculate creep strain and creep damage using the Liu and Murakami material model. Load and boundary conditions were applied to the CT model via rigid pins which were modeled and placed at pin holes. Details of load application to CT models using rigid pins are given in [11]. 


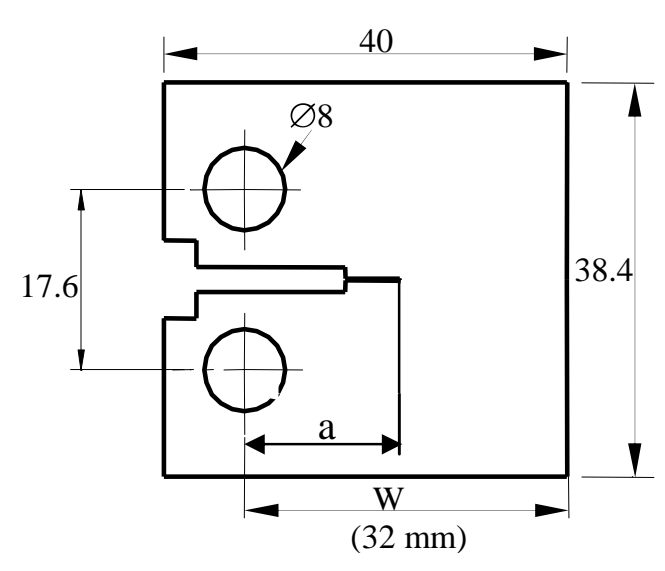

(a)

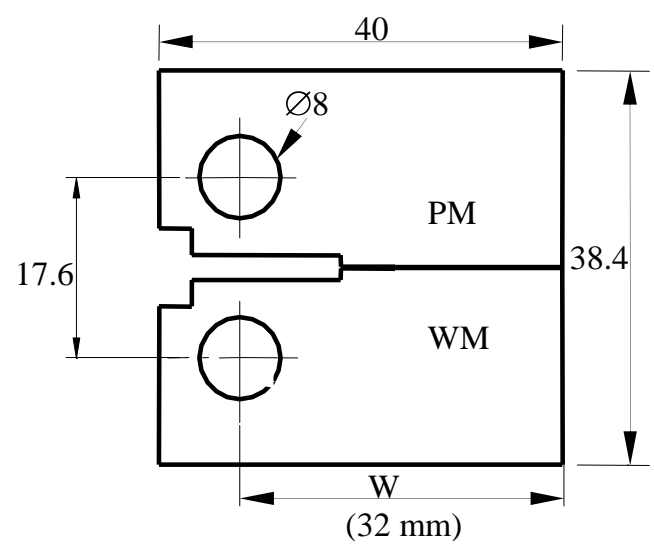

(b)

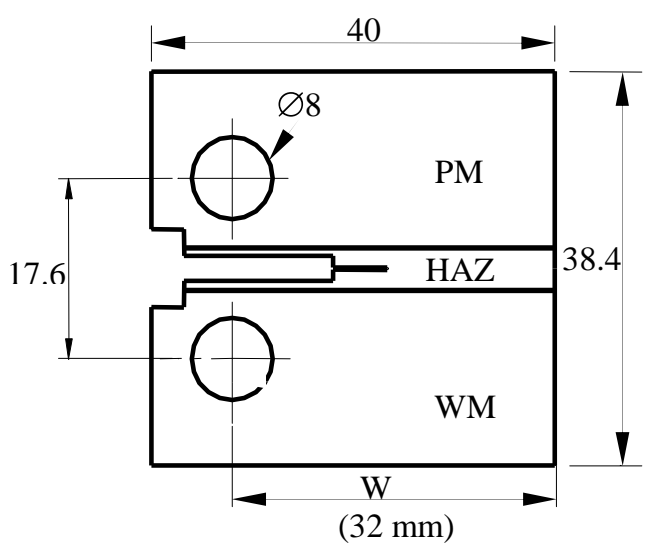

(c)

Figure 2: Geometies and dimensions of the used CT models: (a) single-material model; (b) bi-material model, e.g. PM-WM model, and (c) three-material model. 


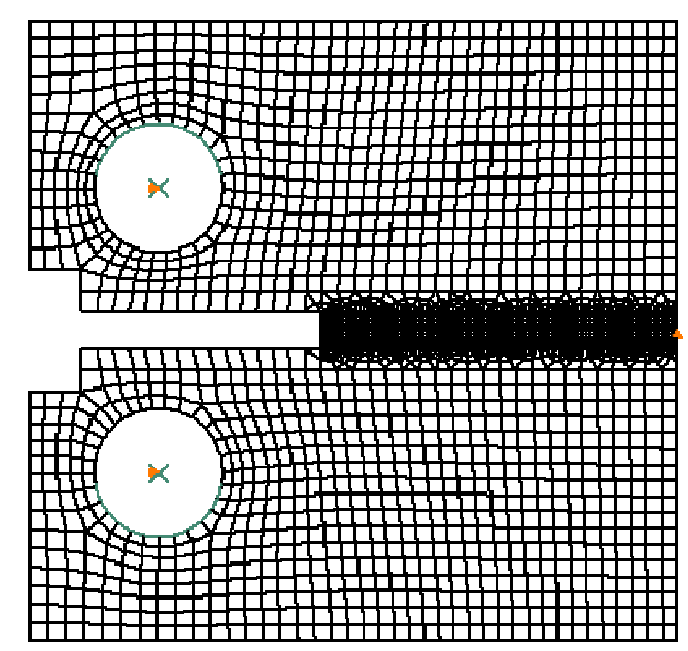

Figure 3: Finite element mesh of CT model; fine elements were used in the vicinity of the crack tip while coarse elements were used elsewhere.

\section{RESULTS AND DISSCUSION}

A set of FE analyses were carried out on different configurations of CT models using material properties for the P91 weld, at $650^{\circ} \mathrm{C}$. The Liu and Murakami model, given in equations (2), was used to calculate creep damage, $\omega$, at each integration point of each element, where $\omega=0$ indicates that the material is not damaged and $\omega=1$ indicates that the material is fully damaged (failure). As the value of $\omega$ approaches unity within an element, the creep strength of the material reduces very rapidly. To model the effects of damage, the modulus of elasticity, $\mathrm{E}$, is reduced as the $\omega$ increases according to the relationship $E_{i+1}=\left(1-\omega_{i}\right) E_{i}$, where $E_{i+1}$ is the modulus of elasticity at time increment $i+1$ and $E_{i}$ is the modulus of elasticity at time increment $i$. Throughout this study, the maximum value of $\omega$ was set to 0.99 . This is to avoid any numerical errors that could arise from using the maximum value of $\omega=1$. As the value of $\omega$ approaches the critical value, 0.99, at an integration point within an element, its modulus of elasticity, E, approaches zero, and hence, it cannot support any more load and is, therefore, considered to be 
removed from the model, i.e. the element was failed. When this failed element was located on the crack path, the crack length was considered to increase by the amount of the element size.

\subsection{Results of single-material models}

Predicted damage in the single-material CT models is shown in Figure 4. It can be seen that the damage is uniformly distributed ahead of the crack tip for the PM CT model. For the WM CT model, the damage is localized in a narrow zone ahead of the crack tip. This localization of damage accelerates the damage rate and, therefore, reduces the failure time of the model. The fully damaged elements, where $\omega=0.99$, represent the crack extension. The resulted creep crack growths in the single-material models are shown in Figure 5. It can be seen that the CCG curves for the two models are quite similar; each curve has apparent steady state CCG followed by tertiary CCG. The primary CCG has not been modelled in this study, for the sake of simplicity. It can also be seen that the failure time of the WM CT model is about 5\% of that for the PM CT model. This can be attributed the brittleness of the WM compared to the PM. This brittleness can be noticed from the uniaxial behaviour of the two material which is shown in Figure 6, [10]. Figure 7 shows that the average creep ductility of the WM is about $3.8 \%$ which is more than an order of magnitude that of the PM $(\approx 36 \%)$. This remarkable difference in failure ductility justifies the remarkable difference in CCG, failure time between the PM and WM.

Figure 8 compares the CCG rates from the PM model to those from the WM model. It can be seen that the creep crack growth rates for the WM are more than an order of magnitude higher than those for the PM model. It is worth mentioning that it is impractical to attain the damage shown in the WM case as the specimen yield when the crack length reaches a value where the stress in the vicinity of the crack is more than the yield stress of the CT material. 


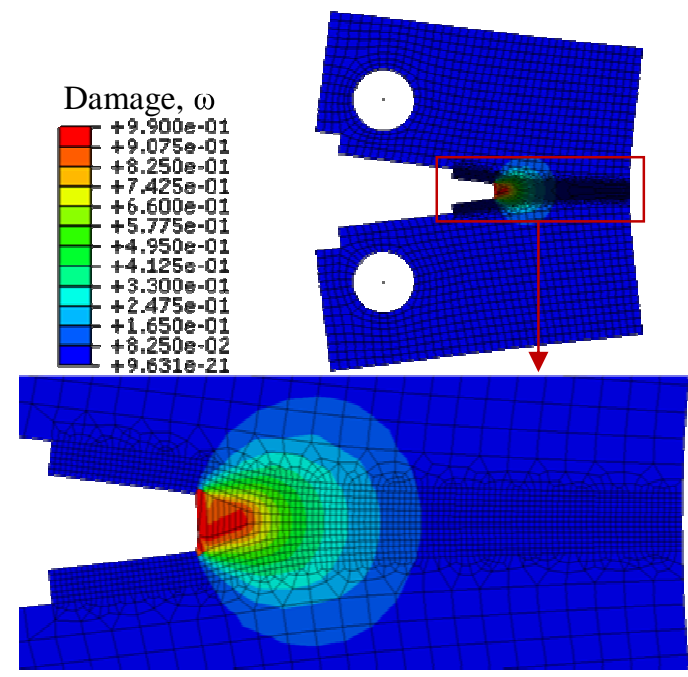

(a)

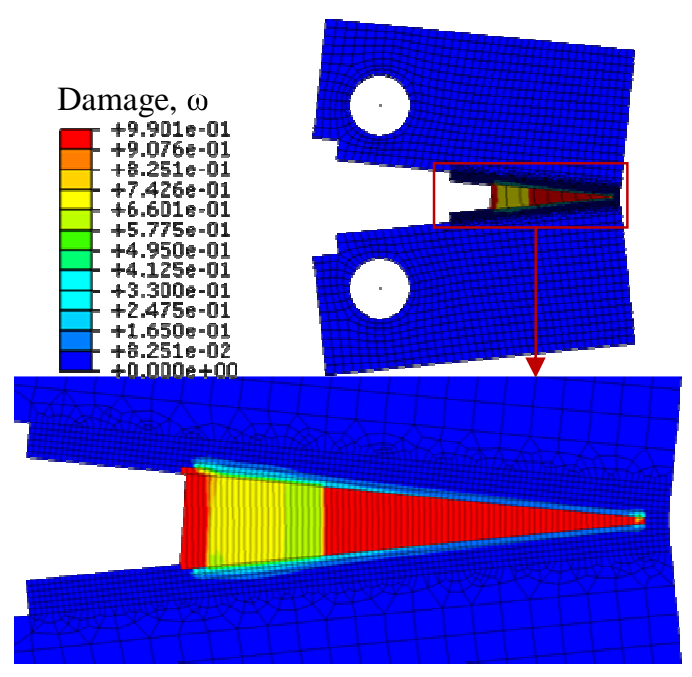

(b)

Figure 4: Damage prediction in (a) PM CT model and (b) WM CT model.

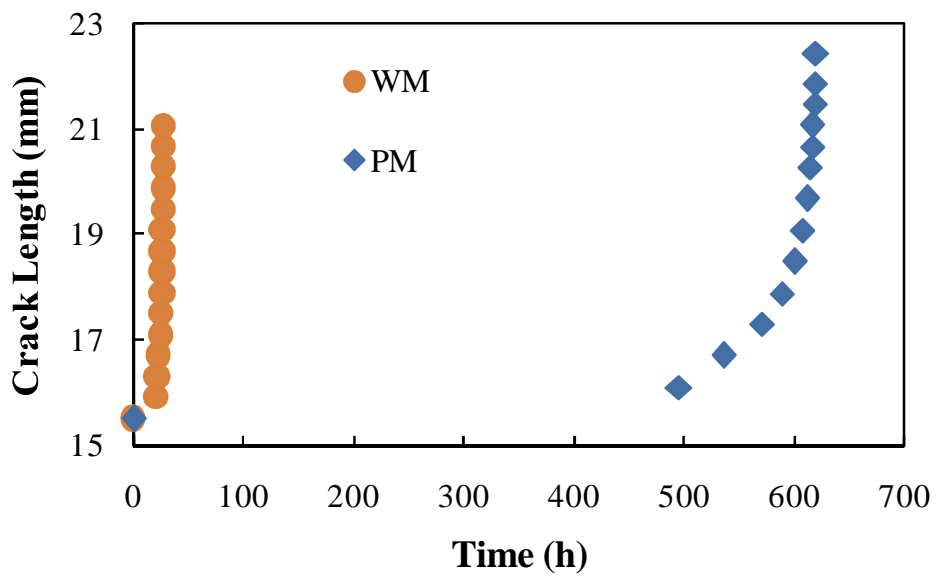

Figure 5: FE creep crack growths (CCG) for the PM and the WM CT models. 


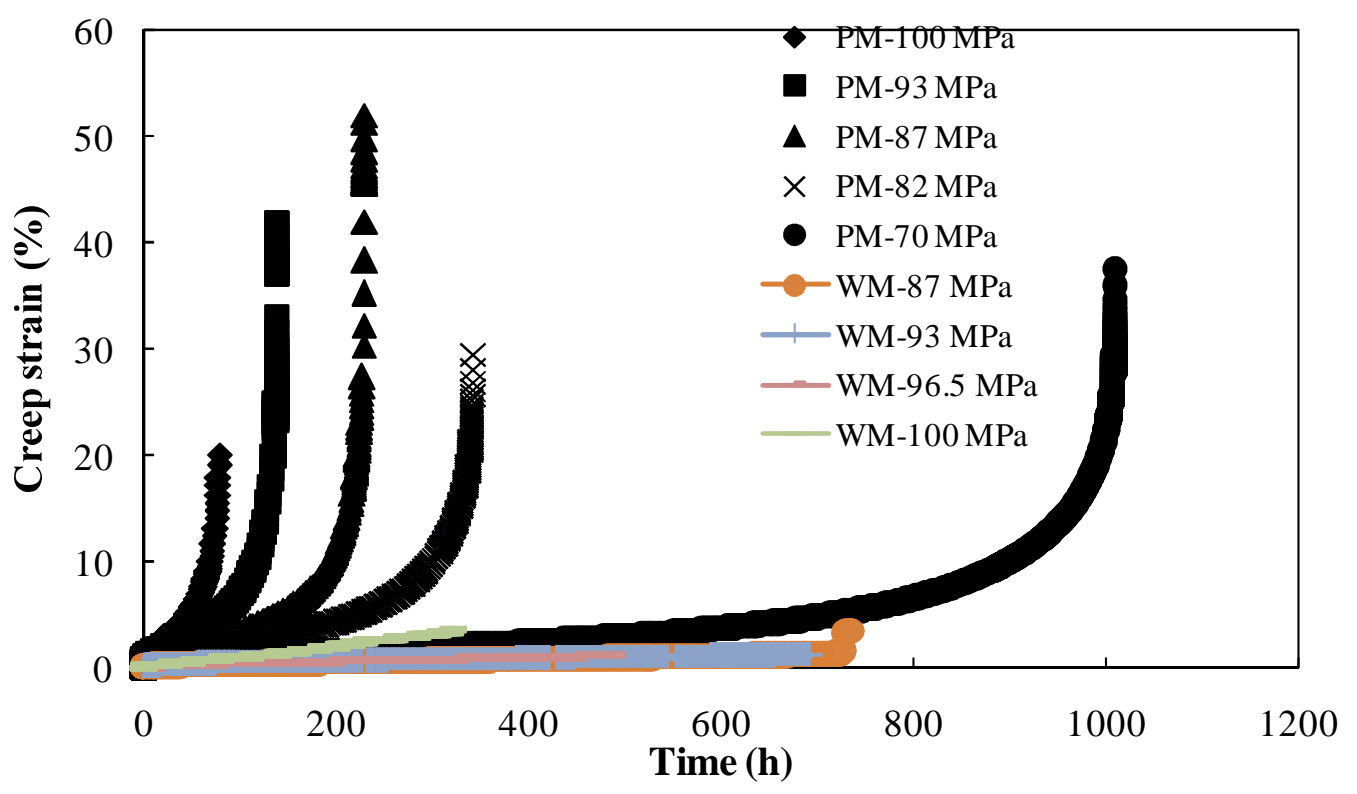

Figure 6: Creep strain curves for P91 parent material and weld material.

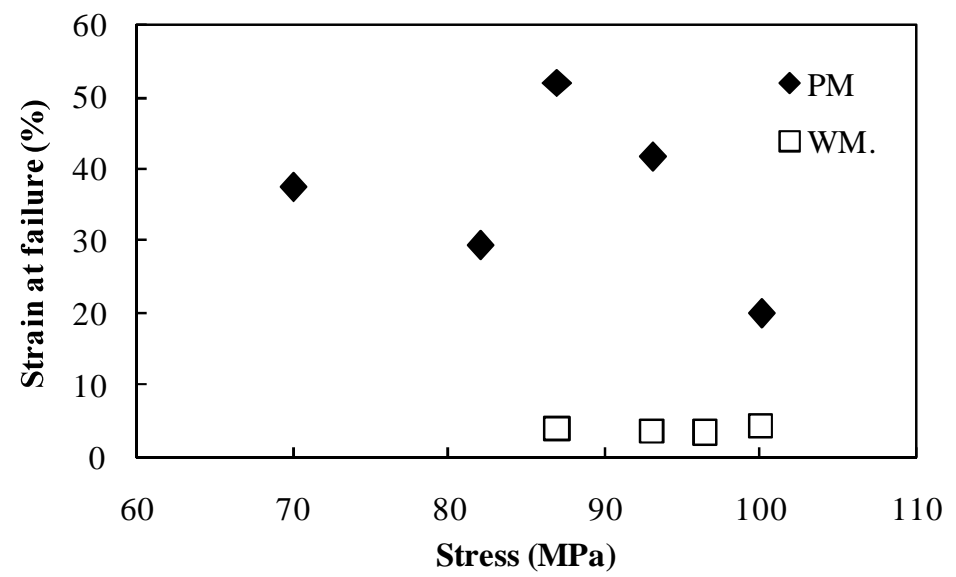

Figure 7: Ductility of P91 WM compared to that of P91 PM. 


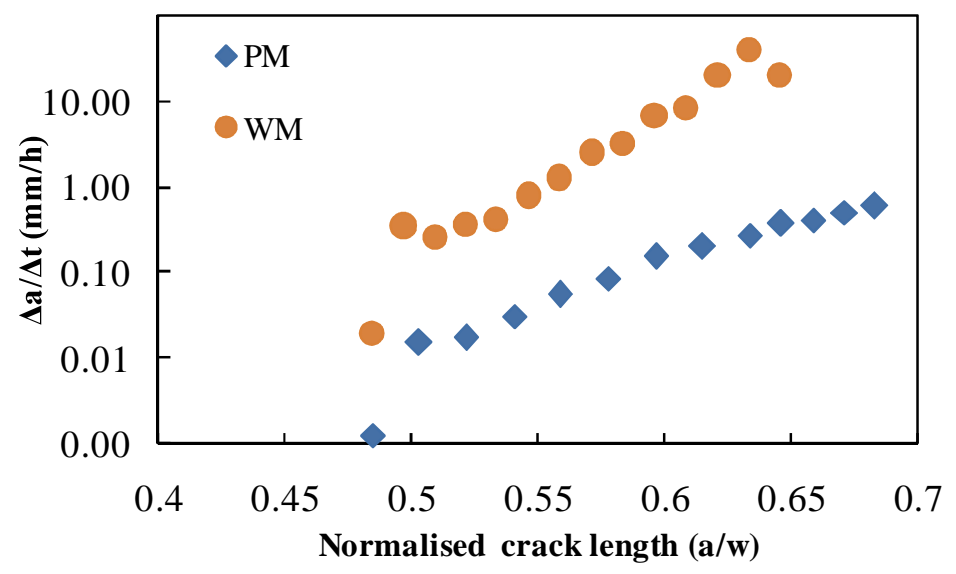

Figure 8: Creep crack growth rates against normalized creep crack growth, for PM and WM CT models.

\subsection{Results of bi-material models}

Two bi-material CT models were analyzed, i.e. the PM-HAZ model and the PM-WM model under the same loading conditions. For the P91 weldment, it was found that the uniaxial tensile creep strength of the WM is higher than that of the PM and the creep strength of the PM is higher than that of the HAZ [12]. Consequently, each of the bi-material models studied consists of a stronger material and a weaker material. Figure 9 shows the damage predicted in the PM-HAZ and in the PM-WM models, respectively. Higher damage can be seen in the vicinity of the crack tip in the weaker material, i.e. the HAZ in the PM-HAZ model and the PM in the PM-WM model. Therefore, it can be said that for the bi-material situations, the creep strength of the weakest weldment constituent largely affects the creep crack growth and, hence, the failure life of a weldment. Figure 10 compares the FE CCG for the bi-material model to that of the singlematerial models. It can be seen that the CCG of the PM-WM models is the same as that of the PM model. Furthermore, although the CCG for the PM-HAZ model has the same trend as that 
for the PM model, the failure time for the PM-HAZ model is about one half of that for the PM

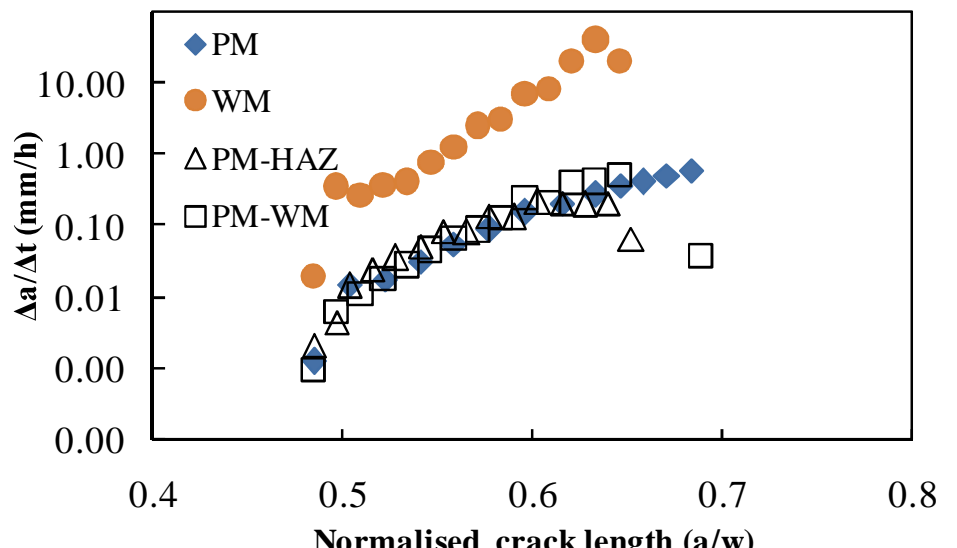

model.

Normalised crack length $(\mathrm{a} / \mathrm{w})$

Figure 11 compares the CCG rates for the single-material and bi-material models. It can be seen that, except that for the WM model, CCG rates for the all of the other models are similar.

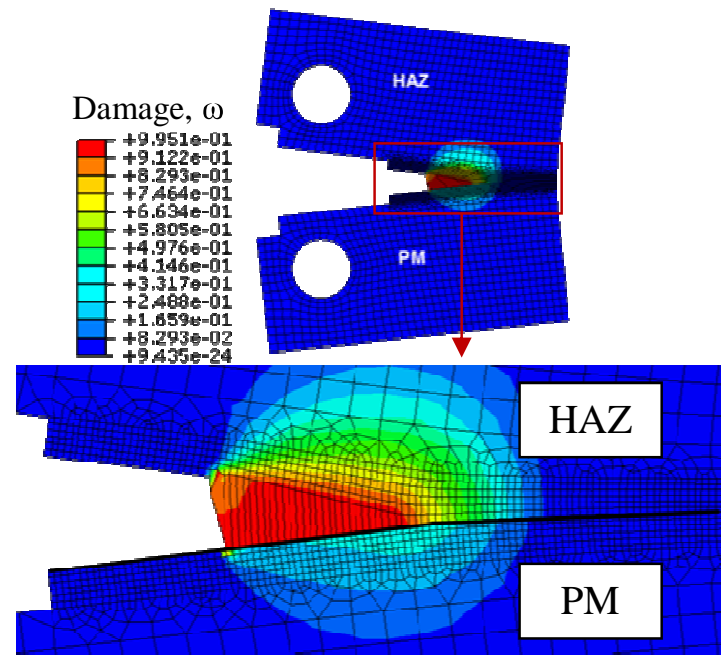

(a)

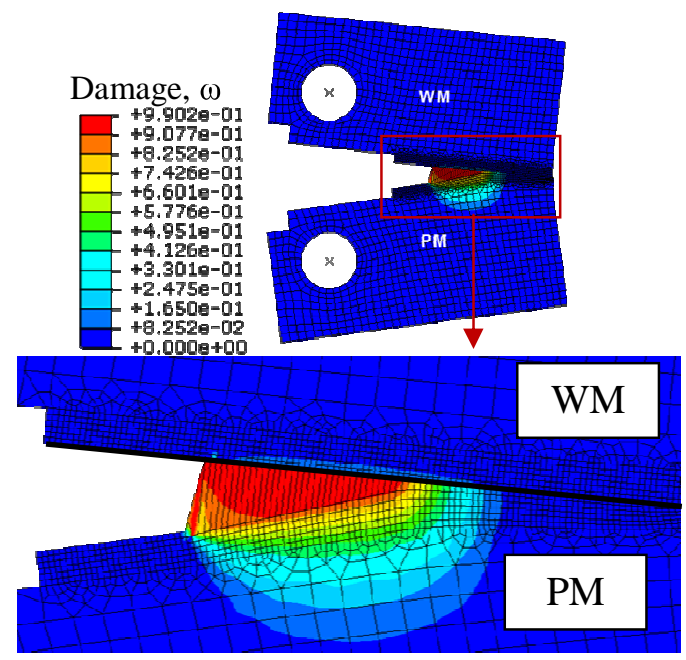

(b)

Figure 9: FE damage prediction in (a) PM-HAZ CT model and (b) PM-WM CT model. 


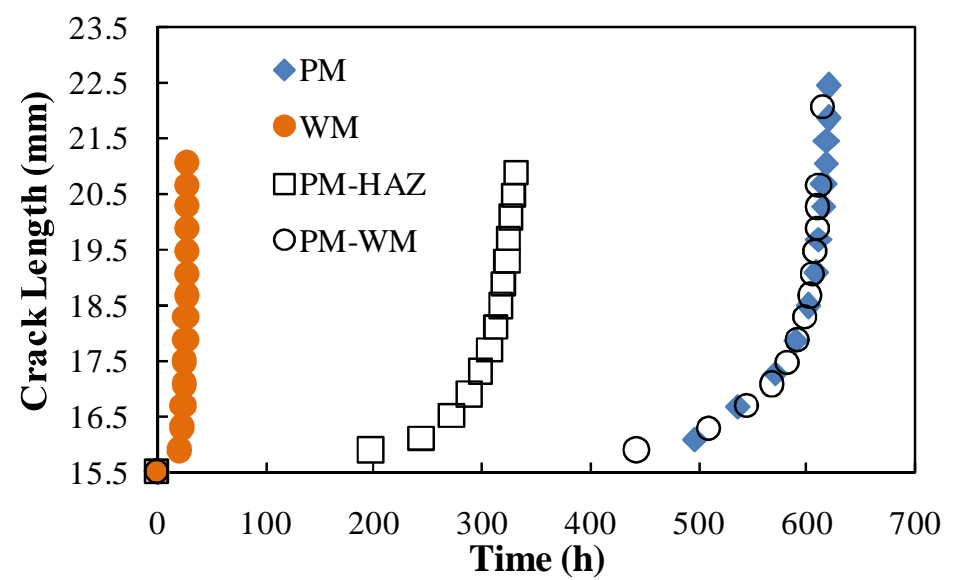

Figure 10: FE creep crack growth of bi-material CT models compared to that for single-material models.

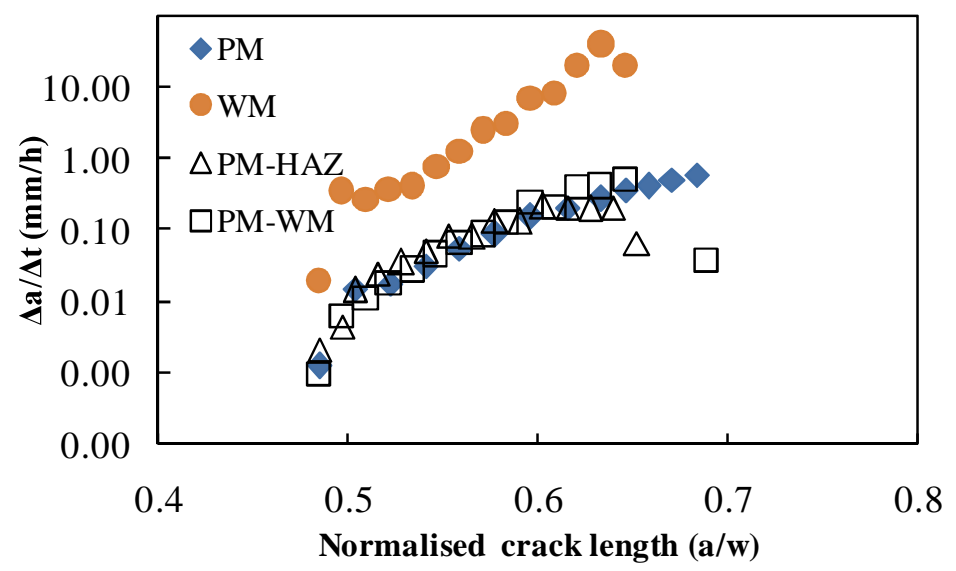

Figure 11: Creep crack growth rates against normalized creep crack growth for single-material and bimaterial models.

\subsection{Results of three-material models}

For the three-material CT models, three FE analyses were carried out under the same loading conditions but with different crack position (see Table 3). The FE analyses were left running 
until the time increment, within the analyses, dropped to impractical values then the analyses was stopped by the user.

Figure 12 compares the FE predicted damage, and hence the CCG, in the three-material CT models. In all of the three cases, higher damage can be seen in the HAZ while low damage appears in the PM but almost no damage appears in the WM. The fully damaged elements, i.e. where $\omega=0.99$, are considered as CCG. The CCGs for the three-material models are shown in Figure 13. Results of the single-material models, i.e. PM and WM, are also included. It can be seen that, for the bi-material model, the CCG of a crack that is located on the interface of two materials is the same as the CCG for the single-material model made of the weaker material.. For the three-material models, as seen in Figure 13, the CCGs for both the 3mat-PM/HAZ and the 3mat-WM/HAZ models are determinated by the HAZ properties. These CCGs are similar to each others and different from those of the PM or the WM. This can be attributed to the relatively small width of the HAZ, $2.4 \mathrm{~mm}$, and the constancy of material properties across the HAZ. It can also be seen that the failure time for the 3mat-PM/HAZ and for the 3 mat-WM/HAZ are less that for the 3mat-middle-HAZ model. This is because the location of initial crack on material interface accelerates its growth, due to high stress triaxiality found at the materials interface. The creep crack growth rates for the three-material models are similar to that for the PM model, see Figure 14. In Figure 14, it can be also seen that the CCG rate for the 3matmiddle-HAZ model is slightly less than that for 3mat-PM/HAZ and 3mat-WM/HAZ models. 


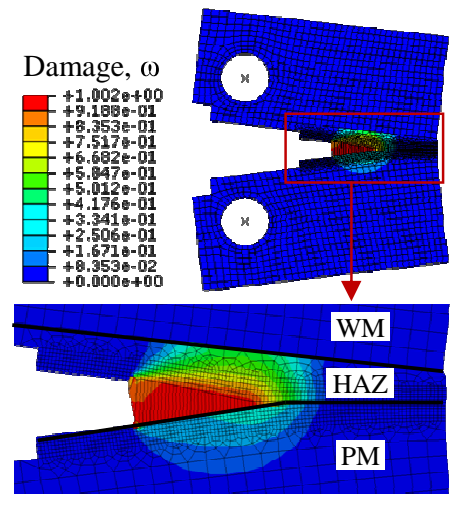

(a)

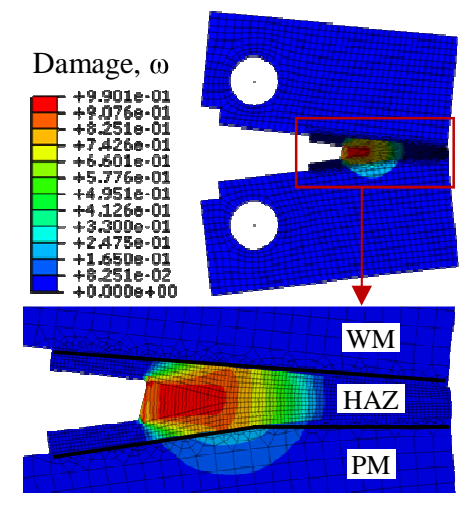

(b)

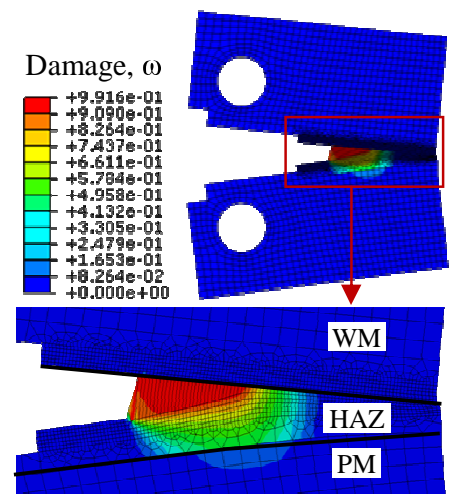

(c)

Figure 12: FE damage prediction in three-material CT models when the crack tip was located (a) on the PM-HAZ interface, (b) at the middle of the HAZ and (c) on the WM-HAZ interface.

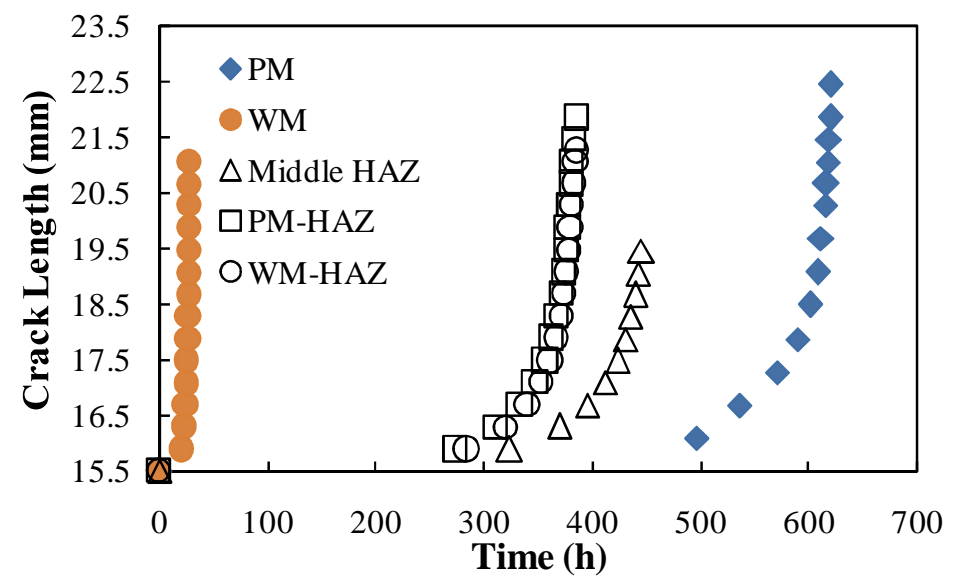

Figure 13: FE creep crack growth of three-material CT models compared to that for single-material and models. 


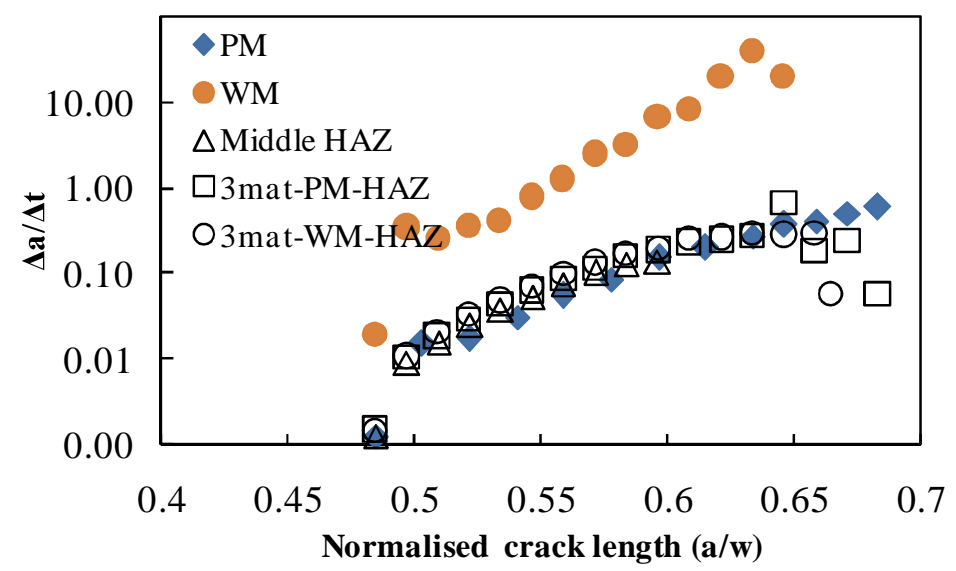

Figure 14: Creep crack growth rates against normalised creep crack growth for three-materials CT models compared to those for single-material CT models.

\section{CONCLUSIONS}

The effects of the location of cracks on creep crack growth, in a P91 weldment, were investigated. Single-material, bi-material and three-material CT models were used. The Liu and Murakami damage model was used to predict the damage, and hence the CCG, in the models. For the bi-material and three-material models, the initial cracks were located on the boundary of the two materials of different creep strengths. The results obtained showed that, the CCG and the CCG rates in the WM CT models are much higher than those in the PM CT models. This may be attributed to the creep brittleness of the WM when compared to that of the PM. For the bimaterial models, since the initial crack was located on the material interface, the CCG and CCG rates are similar to those for the weaker material of the two materials. At the material interface, high triaxiality exists and, therefore, enhances the CCG and CCG rates. Crack tip is subjected to further triaxiality due plane strain conditions arose at the crack tip. This cumulative triaxiality at the crack tip makes the material behaving at a very brittle material. This is obvious in three- 
material models where the CCG and the CCG rates for the 3mat-PM/HAZ and for the 3mat-

WM/HAZ are higher than those for the 3mat-middle-HAZ models.

Damage distribution depends on material properties. The results shown in Figure 4, Figure 9 and Figure 12 for single materials, bi-material and three-material models, respectively, indicate that the damage is uniformly distributed in both the PM and HAZ materials while it is localized in the WM. This localization of damage leads to the increase in the CCG and CCG rates and decrease in the failure life of the WM CT model.

\section{REFERENCES:}

[1] Liu, Y. and S. Murakami, Damage localization of conventional creep damage models and proposition of a new model for creep damage analysis. JSME International Journal 1998. 41(1): p. 57-65.

[2] Schuller, H.J., L. Hangn, and A. Woitschek, Cracking in the weld regions of shaped component in hot steam pipelines - material investigations. Der Maschinenschaden, 1974. 47(S): p. 1-13.

[3] Hongo, H., M. Tabuchi, and Y. Takahashi, Microstructures and Type-IV Creep Damage of High Cr Steel Welds. Journal of Solid Mechanics and Materials Engineering, 2009. 3(3): p. 464-474.

[4] Hyde, T.H. and W. Sun, Determining high temperature properties of weld materials. JSME International Journal of Solid Mechanics \& Material Engineering, 2000. 43(4): p. 408-414.

[5] Tabuchi, M., T. Watanabe, K. Kubo, M. Matsui, J. Kinugawa, and F. Abe, Creep crack growth behavior in the HAZ of weldments of W containing high Cr steel. International Journal of Pressure Vessels and Piping, 2001. 78(11-12): p. 779-784.

[6] Le Mat Hamata, N. and I.A. Shibli, Creep crack growth of seam-welded P22 and P91 pipes with artificial defects. Part II. Data analysis. International Journal of Pressure Vessels and Piping, 2001. 78(11-12): p. 827-835.

[7] Allen, D.J., B. Harvey, and S.J. Brett, "FOURCRACK"--An investigation of the creep performance of advanced high alloy steel welds. International Journal of Pressure Vessels and Piping, 2007. 84(1-2): p. 104-113.

[8] Hyde, T.H., M. Saber, and W. Sun, Testing and modelling of creep crack growth in compact tension specimens from a $P 91$ weld at $650^{\circ} \mathrm{C}$. Engineering Fracture Mechanics, 2010. 77(15): p. 2946-2957. 
[9] Sun, W., C.J. Hyde, T. Hyde, A. Becker, R. Li, and M. Saber. Finite Element Analysis of Creep Crack Growth for Compact Tension and Thumbnail Crack Specimens. in ICAPP 2011. 2011. Nice, France.

[10] Hyde, T., W. Sun, A. Becker, and J. Williams, Creep properties and failure assessment of new and fully repaired $P 91$ pipe welds at $923 \mathrm{~K}$. Proceedings of the Institution of Mechanical Engineers, Part L: Journal of Materials: Design and Applications, 2004. 218(3): p. 211-222.

[11] Saber, M., Experimental and Finite Element Studies of Creep and Creep Crack Growth in P91 and P92 Weldments in Mechanical. 2011, Nottingham: Nottingham, UK. p. 248.

[12] Hyde, T.H., M. Saber, and W. Sun, Creep crack growth data and prediction for a P91 weld at $650^{\circ} \mathrm{C}$. International Journal of Pressure Vessels and Piping, 2010. 87(12): p. 721-729.

[13] ASTM E 1457-00, Standard test method for measuerment of creep crack growth rates in metals. Vol. 3(1). 2001: Annual book of ASTM standards.

[14] ABAQUS, ABAQUS 6.7 Standard user manual. 2007, USA: ABAQUS, Inc. 


\section{Nomenclature:}

A

a

B

$\mathrm{n}$

$\mathrm{q}_{2}$

$\mathrm{t}$

$t_{f}$

$\alpha$

$\varepsilon_{i j}$

$S_{i j}$

$\sigma_{e q}$

$\sigma$

$\sigma_{1}$

$\sigma_{\mathrm{r}}$

$\chi$

$\omega$

$\varepsilon^{\mathrm{c}}$

$\dot{\varepsilon}$

$\phi$

Material constant in Norton's creep law, Kachanov creep damage model, and Liu and Murakami creep damage model

Crack length

Material constant in Kachanov creep damage model or

full thickness of compact tension specimens

Material constant in Norton's creep law, Kachanov creep damage model, and Liu and Murakami creep damage model

Material constant in Liu and Murakami creep damage model

Time

Failure time

Multiaxial parameter; material constant

Creep strain tensor

Deviatoric stress tensor

Equivalent, von Mises, stress

Stress

Maximum principal stress

Rupture stress

Material constant in both Kachanov, and Liu and Murakami creep damage models

Damage parameter, ranging from 0.0 (no damage) to 1.0 (full damage)

Creep strain

Creep strain rate

Material constant in Kachanov creep damage model 
- Liu and Murakami damage model was successfully used to predict creep crack growth.

- Material properties greatly affect the damage distribution.

- Creep crack growth is greatly affected by neighbouring materials.

- P91 weld showed significant brittleness when compared to P92 parent material. 